\title{
Corrective Aspects of ICT in the Development of Musical Hearing in Children with Hearing Disabilities
}

\author{
Sofya Aksenova ${ }^{1, a *}$ \\ 1 The Musical College named after the Gnessins of the Gnessin Russian Academy of Music, \\ 121069, 38, building 1, Povarskaya str., Moscow, Russia \\ aaksenova sofia@mail.ru \\ ${ }^{*}$ Corresponding author
}

Keywords: information and communication technologies, modern sound environment, hearing, music, correctional potential, hearing impaired children, deaf-and-dumb pedagogy

\begin{abstract}
The article provides an overview of the use of new information and communication technologies necessary in modern sound environment to improve musical hearing, proposing a set of technical innovation tools to correct the deficiencies in the development of musical hearing and make it possible to use these simulators in deaf-and-dumb pedagogy. Simulators in deaf-and-dumb pedagogy, correction of musical hearing, identification of electrocardiogram rhythms, differentiation of sounds similar in articulation are considered.
\end{abstract}

\section{Introduction}

In the modern world, there is an acute problem of hearing, which is caused by the variety of noise components of our environment and the layering of sounds accompany a child from birth: loud pulsating music, often running television, the roar of cars outside the window, etc. Parents can not immediately understand that a child has a hearing problem, often congenital, which is a consequence of the fact that previous generations have extremely thoughtlessly exploited a hearing aid. There are new music technologies that were designed to take into account the problem of hearing correction, when visual, motor, and rhythmic correctors (simulators) come to the aid of hearing, which can help restore or re-acquire hearing skills.

\section{Methodology}

The article presents an analysis of the use of modern simulators for the development of hearing in deaf-anddumb education. Relying on the pedagogical experience in the development of music and timbre hearing in vocalists as part of advanced training for teachers on the academic vocal of music schools, the author explores the possibility of using extrapolation technologies of pedagogical experience in a corrective pedagogical situation.

\section{Research}

Consider the use of ICT for the development of musical hearing in the standard and correctional pedagogical situation.

In the field of music, they are used in the pedagogical practice of the program for the development of musical hearing, consolidation of knowledge on the elementary theory (EarMasterPro, EarMasterSchool, EarPower, Sight-SingingTrainer, and others) [1]. For example, the EarMasterProRus hearing instrument from the eMedia Music Corporation is a universal training program for training musical hearing, rhythm and vocal skill. Many exercises from simple to complex will help to become a musician in your field. Audacity (audio editor) has all the necessary functions for professional work with soundtracks, is a free analogue of SoundForge. In this program, students master the basic skills of working with digital sound, allowing you to visually understand the problems of intonation. As a result, they can independently record their own or someone else's performance, process it, remove any defects, apply special effects, save to any popular format (WAV, MP3), and can work with any sound files (from the Internet, from a CD etc.). They will be able to easily cut off any composition, mount a few, change the tonality, remove noise, etc. This knowledge will help to create sound for school events and to participate in multimedia project competitions. 
The Windows Movie Maker is a video editor. Despite the fact that this program or its analogue, the Windows Leif Film Studio, are on any computer where Windows is installed, very few people, even from the "advanced" users, know about it [2]. However, this program can help very much. With its help, one can, for example, create an educational film for music literature lessons, make video accompaniment to any event, present own achievements, etc. In conjunction with the Windows Movie Maker, we use epy iWisoft Free Video Converter. Using the maximum of all the capabilities of these video programs, students often create very professional videos.

The Singing Tutor allows the user to test several notes of tone in the range that he or she has chosen. This is done in order to control the sound quality and tone before recording, the program uses a powerful and modern digital signal processing algorithm to measure the pitch of the voice and connect the microphone to the computer sound card. The Singing Tutor has a simple and intuitive interface. If necessary, it can partially replace the teacher.

Consider as an illustration one of the exercises: the Singing Tutor offers a variety of exercises for learning the voice. One can also create own exercises to improve vocal skills, understand the cause of problems with unclean intonation, poor articulation.

The Rhythm Tutor is a rhythm feeling simulator that allows one to strengthen an organized approach to the identification of electrocardiogram rhythms. There are two types of exercises. The mode A allows a user conduct in a rhythm that he/she hears. Or one can work in the mode B, in which a user sees the rhythm and selects a sound that matches. At the end of each session, there is an opportunity to record, save, and send results to a teacher to monitor students' performance [4].

All these programs and simulators are designed so that modern beginner vocalists have the opportunity to learn about the shortcomings of intonation and rhythmic deviations visually with the help of simulators. Accordingly, the same problems exist in children who need hearing correction [3]. Let's consider them in more detail.

So, multimedia presentations are created to work with the automation of sounds, the rhythmicintonational structure of speech. For each sound studied, sound pronunciation profiles, pictures that fix sounds in all positions are selected to differentiate sounds similar in articulation, speech material for automation and sound differentiation. In developing the skills of the speech rhythmic-intonational structure, a student first imitates a teacher, and later he/she is offered a recorded speech material (with emphasis on accent, orthoepic norms, and pauses) [5].

Today, there is a fairly large set of information technology tools that allow a modern teacher to expand the circle of pedagogical competences [6].

Currently, a number of specialized software and methodical complexes of new means of correction and general development of children with impaired hearing have been developed. For example, "The World Behind Your Window" is a complex of programs aimed at mastering communication skills. In the process of working with the program, each student interacts with the "computer man". The program in various situations requires both monosyllabic answers and expanded ones [8].

The Delpha-130 complex ("Visible Speech" IBM) contains a new pedagogical technology for solving problems of correction and formation of pronunciation. Sounds are pronounced in the microphone cause, respectively, as a change of pictures on the computer screen. Working out the elements of speech becomes a fascinating game that gives the effect of correcting sound skills necessary for learning. A variety of exercises and games allows one to develop speech breathing, fusion of speech, to form the correct pronunciation of sounds in syllables, words, phrases, phrases, the ability to change the volume, rate of speech, and also to eliminate the nasal tone of the voice, i.e. the student is gradually improving. Methodological guidelines determine the principles of incorporating a new technology into the general system of pedagogical correction of the pronunciation side of oral speech.

Special corrective techniques are used to work on pronunciation: the use of auditory self-control, the imitation of the teacher's articulation, the use of tactile-vibration sensitivity, elements of phonetic rhythm. When working with the modules "Volume" and "Intensity and Voice," one should use an additional set of visual material, such as pictures and plates with speech material depending on the topic of the lesson. When 
working on the rhythmic structure of a word, it is necessary to select and use two- and three-syllable multiimpact words. At the very beginning of work, it is advisable to use tablets with words in combination with the presentation of pictures. The selection of speech material is carried out taking into account the age characteristics and pronunciation of the hearing impaired children [9].

Children with hearing impairments master verbal speech and, in particular, its oral form only under conditions of special training, which is based on the use of residual hearing involving visual, tactile, and motorized analyzers and the widespread use of technical means (sound amplifying equipment, vibrators, and visual devices) and modern information technologies (I. G. Bagrova, L. S. Godin, T. K. Korolevskaya, E. P. Kuzmicheva, O. N. Kukushkina, etc.) $[7,11,12,13,14,15]$.

A new task of modern special education is the identification of that part of deaf children who are most capable of programming as a special type of activity. "Playing, learning Logo" implements a methodical approach to identifying these children in the process of long-term, focused language learning being organized in the form of a game.

In Western Audiology, the Video Voice Speech Training System program (www.videovoice.com) is considered one of the universally recognized tools. The full version of Video Voice includes game simulators (Fun \& Gamesmenu) and numerous means of visual control of pronunciation (Formant Displays, P-A-R Displays, Assessment Displays) [10].

\section{Conclusion}

The pedagogical and correctional potential of using ICT in the development of musical hearing, including children with disabilities in Russia, remains a promising research task. Local examples of pedagogical practice in this direction show and confirm the possibility of extrapolating the pedagogical experience to develop the vocalists' musical ear and solving the intonation problems (intonation problems) of vocalists into the pedagogical practice of correcting the hearing of children with developmental disorders.

\section{References}

[1] Aksenova, S. S. (2015). The importance of the use of ICT in modern music pedagogy. In Proceedings of the International Scientific and Practical Conference "Teacher's skill and innovation in education" (pp. 215-218). Moscow, Russia.

[2] Aksenova, S. S., \& Kozlov, O. A. (2015). Electronic educational resources in music education. In Proceedings of the IV International Scientific and Methodological Symposium "ERNO - 2015” (pp. 88-93). Rostov-on-Don, Russia: Publishing House of the Southern Federal University.

[3] Bitova, A. L., Konstantinova, I. S., \& Tsyganok, A. A. (2007). Place of music therapy in the system of helping a child with developmental disabilities. In Training and education of children with developmental disabilities (pp. 56-69). Moscow, Russia

[4] Vilochkina, T. M. (1990). Listening to music in rhythmic classes. Defectology, 2, pp.15-22

[5] Zubenko, N. P. (2007). Computer kaleidoscope: the use of computer presentations in primary school. Mozyr: Assistance.

[6] Lizunova, L. R. (2005). The use of information and communication technologies in speech therapy. Speech therapist, 7. Retrieved from LogogoPortal.ru/statya-12871.html

[7] Medvedeva, E. A. (2002). Musical education of children with developmental problems and corrective rhythm. Moscow, Russia: Academy.

[8] Gorbunova, I. B., \& Chudina, V. P. (Eds.) (2017). Music and computer technology. In Electronic musical instruments: Theory and practice of performance. SPb., Russia: Publishing House the Herzen State Pedagogical University of Russia.

[9] Nazarova, N. M. (2000). Special pedagogy. Moscow, Russia.

[10] Petrushin, V. I. (2000). Music psychotherapy. Moscow, Russia: Vlados. 
[11] Rechitskaya, E. G., \& Soshina, E. A. (2002). The development of the creative imagination of younger students in conditions of normal and impaired hearing. Moscow, Russia: Vlados.

[12] Aksenova, S. S., \& Arinushkina, A. A. (2017). Social media in the professional development of a teacher on vocal by the Graduate School of Art and Music School. Pedagogy and Education, 4, pp. 1017.

[13] Aksenova, S. S., \& Arinushkina, A. A. (2018). The development of an institutionalized personalized educational environment during the advanced training of teachers on vocals by the Graduate School of Art and Music School. Modern Science: Actual Problems of Theory and Practice, 3/2, pp. 65-68.

[14] Aksenova, S. S., \& Arinushkina, A. A. (2017). Foreign experience in the use of information and communication technologies in the vocational teacher's vocational activity. Education Management: Theory and Practice, 4(28), pp. 73-77.

[15] Robert, I. V. et al. (2017). Forecast of the development of education informatization. Revista ESPACIOS, 38, 40. Retrieved from http://www.revistaespacios.com/a17v38n40/a17v38n40p32.pdf

[16] Neustroev, S. S. et al. (2018). Legal regulation of health restrictions and current law enforcement practices in the organization of training. Journal of History Culture and Art Research, 7(2), pp. 58-71. 